\title{
Gênero e Sexualidade em uma Discussão Virtual sobre a Marcha das Vadias
}

\author{
Gabriela Sagebin Bordini ${ }^{1}$ \\ Universidade Federal do Rio Grande do Sul, Porto Alegre, RS, Brasil \\ Tania Mara Sperb \\ Departamento de Psicologia do Desenvolvimento e da Personalidade da Universidade \\ Federal do Rio Grande do Sul, Porto Alegre, RS, Brasil
}

\begin{abstract}
Resumo
No mundo ocidental, há uma histórica articulação entre os conceitos de gênero e sexualidade. Tradicionalmente, diferentes significados são associados às sexualidades de homens e mulheres, incluindo a concepção de que o homem e a mulher formariam um par com características e comportamentos opostos que se complementam. No entanto, gênero e sexualidade são construções históricas e culturais, em permanente elaboração, instáveis e provisórias. Diante disso, este estudo procurou investigar o processo de negociação dos significados associados às sexualidades de mulheres e homens, na atualidade, por parte de jovens universitários em um ambiente virtual. Para tal, foram analisados os comentários de usuários de um blog, voltado ao público universitário gaúcho, a um texto postado sobre o movimento Marcha das Vadias. Identificou-se o emprego de diferentes repertórios para interpretar as sexualidades de mulheres e, portanto, de homens, o que revelou a atribuição tanto de significados tradicionais quanto atípicos às sexualidades, por parte de universitários.
\end{abstract}

Palavras-chave: Gênero, sexualidade, internet, repertórios interpretativos, jovens.

\section{Gender and Sexuality in a Virtual Discussion about the Slut Walk}

\begin{abstract}
In the occidental world, the concepts of gender and sexuality are historically linked. Traditionally, different meanings are associated to men's and women's sexualities, including the idea that man and woman are a pair with opposite characteristics and behaviors that complement one another. Nevertheless, gender and sexuality are cultural and historical constructions, permanently under development, unstable and temporary. Thus, the present work aims at investigating the negotiation of meanings associated to men's and women's sexualities, nowadays, by college students in a virtual environment. With this aim, we analyzed comments to a text on the Slut Walk, published in a blog which is mostly accessed by college students from the south of Brazil. We identified the use of different repertoires by college students to interpret women's sexualities and, therefore, men's sexuality, revealing both traditional and atypical meanings related to sexualities.
\end{abstract}

Keywords: Gender, sexuality, internet, interpretative repertoires, young adults.

Endereço para correspondência: Universidade Federal do Rio Grande do Sul, Instituto de Psicologia, Rua Ramiro Barcelos, 2600, sala 116, Porto Alegre, RS, Brasil 90035-003. E-mail: charlestonbordini@yahoo.com. bresperbt@terra.com.br

Este artigo foi financiado pela Coordenação de Aperfeiçoamento de Pessoal de Nível Superior (CAPES) e pelo Conselho Nacional de Desenvolvimento Científico e Tecnológico (CNPq). 


\section{Género y Sexualidad en una Discusión Virtual sobre la Marcha de las Putas}

\section{Resumen}

En el mundo occidental, los conceptos de género y de sexualidad están históricamente vinculados. Tradicionalmente, diferentes significados están asociados a las sexualidades de los hombres y de las mujeres, incluyendo la idea de que el hombre y la mujer serían un par con características y comportamientos opuestos que se complementan entre sí. Sin embargo, el género y la sexualidad son construcciones culturales e históricas, en permanente desarrollo, inestables y temporales. Así, el presente trabajo tiene como objetivo investigar la negociación de significados asociados a la sexualidad de hombres y mujeres, actualmente, por estudiantes universitarios en un entorno virtual. Para tal, analizamos comentarios a un texto sobre la Marcha de las Putas, publicado en un blog visitado principalmente por estudiantes universitarios del sur de Brasil. Se identificó el uso de diferentes repertorios para interpretar las sexualidades de las mujeres y, por lo tanto, de los hombres, revelando la atribución, sea de significados tradicionales, sea de significados atípicos, a las sexualidades, por parte de los estudiantes universitarios.

Palabras clave: Género, sexualidad, internet, repertorios interpretativos, jóvenes.

O objetivo do presente estudo é investigar o processo de negociação da influência do gênero nos significados associados às sexualidades, empreendido por jovens universitários em um ambiente virtual. Considera-se que o gênero - ser homem, ser mulher - é uma construção histórica e cultural em permanente elaboração, instável e provisória, pois aquilo que se considera masculino ou feminino é determinado pelo que se diz e pensa a respeito dos homens e das mulheres em um dado contexto (Louro, 2001, 2004, 2007 e 2008). A sexualidade também é tida como uma construção, já que os significados que lhes são associados e, portanto, o modo como os indivíduos realizam seus prazeres e desejos, não são dados pela natureza, são construídos e mantidos socialmente por diversas linguagens (Weeks, 2003).

Nas sociedades ocidentais, gênero e sexualidade encontram-se historicamente articulados (Louro, 2009). As definições acerca do que é ser homem e ser mulher influenciam como as sexualidades se realizam. Espera-se, por exemplo, que uma pessoa com características e comportamentos fora dos padrões do masculino ou do feminino apresente características e comportamentos fora dos padrões também no âmbito sexual (Guimarães, 2009; Heilborn, Aquino, Bozon, \& Knauth, 2006; Louro, 2009). Tal entrelaçamento entre gênero e sexualidade merece ser estudado na atualidade, já que, desde o final do século $\mathrm{XX}$, fala-se que uma revolução sexual estaria em curso, envolvendo aspectos como uma maior permissividade sexual - principalmente para as mulheres (Giddens, 1993; Neves, 2007). Paralelamente, desponta o discurso da igualdade, reprimindo-se a expressão flagrante de preconceito contra grupos minoritários (Gouveia et al., 2011).

Nesse contexto, proliferam movimentos de protesto, como a Marcha das Vadias. Esta, conforme Ferreira (2013), inicialmente teve lugar no Canadá, desencadeada pela declaração de um policial que atribuiu o estupro de uma mulher à sua vestimenta. Por meio da comunicação virtual, esse movimento pelo combate à naturalização das violências contra a mulher espalhou-se pelo mundo. No Brasil, de acordo com Helene (2013), o primeiro de tais protestos teve lugar em São Paulo, em 2011, e foi organizado via Facebook por uma mulher com o auxílio de amigos. Em Porto Alegre, a Marcha das Vadias acontece desde 2012, reunindo homens e mulheres de todas as idades na luta contra a violência às mulheres, $\mathrm{o}$ feminicídio, o sexismo, o machismo, ao mesmo tempo em que reivindica os direitos reprodutivos das mulheres e sua liberdade em geral (Fogliatto, 2013, 2014; "Veja as marchas", 2012). 
Segundo Helene (2013), a Marcha das Vadias já ocorreu em cerca de 30 cidades brasileiras, apresentando algumas características em comum: encerramento do protesto em locais que simbolizam a manutenção das violências sobre o corpo feminino (delegacias e igrejas, por exemplo); sistematização da marcha por parte de coletivos formados, sobretudo, por mulheres jovens organizadas de maneira horizontal e descentralizada; elaboração de materiais, como cartazes e vídeos sobre o movimento; e divulgação por meio de redes sociais. Neste sentido, Ferreira (2013) destaca o papel da internet na articulação e divulgação das Marchas das Vadias, bem como espaço que possibilitou o debate e o diálogo entre diferentes setores da sociedade - principalmente em blogs - sobre diversas temáticas relacionadas às assimetrias de gênero.

A internet vem sendo considerada como local de experimentação, transgressão e ativismo, dada a sua característica interacional em conjunto com aspectos como o anonimato, a profusão de informação e os recursos semióticos atualmente disponíveis (de Melo \& Lopes, 2013; Lopes, 2010). Mesmo assim, Ferreira (2013) ressalta que também houve repressão e censura, na internet, em relação à Marcha das Vadias e à discussão gerada pelo movimento. Ou seja, por oferecer acesso a diversas visões de mundo e por ser um ambiente colaborativo e participativo, aparentemente livre do controle institucional, a internet permite o questionamento aos significados hegemônicos, mas não impede a sua reprodução (de Melo \& Lopes, 2013; Lopes, 2010).

Uma das ferramentas virtuais que vem se popularizando como espaço comunicativo e de ação social é o blog: uma página de um usuário - ou mais - na internet, que pode ser atualizada e na qual há espaço para interação, comumente, na forma de comentários (Houaiss \& Villar, 2010). Os blogs podem ser considerados democráticos, pois geralmente são gratuitos e de fácil manejo (Paz, 2003; M. B. P. Santos, Penteado, \& Araújo, 2009). Neles, a produção e a divulgação de informação são executadas pelo público em geral, oportunizando a formação de um pequeno grupo on-line, o que promove integração e diá- logo (Paz, 2003; M. B. P. Santos et al., 2009), podendo levar à negociação de significados.

Além disso, sabe-se que o blog é uma tecnologia comumente utilizada por jovens, inclusive para troca de informações sobre sexualidade (Valli \& Cogo, 2013). Diante disso, optou-se por investigar as negociações da influência do gênero sobre os significados associados às sexualidades de homens e mulheres, durante uma discussão acerca de um texto sobre a Marcha das Vadias, em um blog voltado para universitários.

\section{Método}

Esta é uma pesquisa qualitativa, de caráter exploratório documental. Toma-se a linguagem como um sistema de significação, por meio do qual se atribuem sentidos que constituem e definem a realidade, hierarquizando-a (Silva, 2003). Considerando-se a importância da linguagem, para investigar as negociações empreendidas por jovens, optou-se por analisar as suas participações, na forma de comentários postados em relação ao referido texto, no blog "Facool".

O blog em questão faz parte de um site homônimo voltado ao público universitário do Rio Grande do Sul (cf. http://www.facool.com.br/) e se configura como um blogzine. Este é um termo usado por Luccio e Nicolaci-da-Costa (2010) para descrever os blogs jornalísticos que se assemelham a revistas, incluindo matérias sobre os mais variados assuntos, informações, notícias. No blognize, há uma caixa de diálogos para comentários, que possibilita o debate entre o autor do texto e os leitores.

Dado que o blog em questão é um espaço público, com conteúdo de livre acesso na internet e disponível on-line, não foi necessário obter autorização dos usuários para que suas interações fossem analisadas (Fragoso, Recuero, \& Amaral, 2011). Os excertos do texto sobre a Marcha das Vadias e dos comentários em relação ao mesmo são apresentados aqui tal qual foram postados no $\mathrm{blog}$. Os nomes que apareciam nesses excertos foram modificados por um número precedido de "H", se homem, e de "M", se mulher, para preservar a identidade dos usuários. 
Para analisar a sequência de comentários postados e seus conteúdos, empregaram-se conceitos da psicologia discursiva. Segundo De Fina e Georgakopoulou (2011), esta dedica especial atenção à maneira como as pessoas realizam suas identidades em uma determinada situação interacional por meio do exame dos movimentos linguísticos e comunicacionais em tal situação. Como o foco do presente trabalho é a negociação dos significados associados às sexualidades, considerou-se que o conceito de repertório interpretativo - fundamental na psicologia discursiva - seria o mais adequado.

Esse conceito foi trazido para a psicologia por Potter e Wetherell (1987), sendo definido como um conjunto de termos e metáforas que, em uma situação interacional, é empregado pelos interlocutores para fazer sentido, para caracterizar e avaliar diversos fenômenos. Assim, um repertório interpretativo seria uma espécie de senso comum, que não precisa ser mencionado por completo ou explicitamente, incluindo temas, lugares-comuns e alegorias que estão em circulação em uma dada cultura; algo que serve como uma linha argumentativa habitual, da qual o indivíduo lança mão quando descreve e qualifica atividades, ações, objetos, eventos, enfim, as coisas do mundo (Potter \& Wetherell, 1987; Wetherell, 1998).

Neste trabalho, procurou-se identificar os diferentes repertórios empregados pelos usuários do blog e pelo autor do texto na interpretação da articulação entre gênero e sexualidade. Para tal, o texto postado e os comentários ao mesmo foram lidos exaustivamente. Buscou-se, então, identificar os padrões de significação e os modos de falar que se repetiam no texto e nos comentários. Deu-se especial atenção aos significados que se afastavam dos padrões tradicionais de sexualidade de homens e mulheres, conforme recomendam Edley (2001) e Wetherell (1998).

\section{Resultados e discussão}

É importante ressaltar que não há como ter certeza quanto ao sexo/gênero dos usuários do blog, uma vez que a comunicação virtual permite que um se faça passar pelo outro. Diante disso, aqueles que se apresentaram com nomes masculinos foram aqui referidos como homens, o mesmo valendo para mulheres. Além disso, não há como saber se os usuários eram, de fato, jovens universitários, pois qualquer pessoa pode participar no blog. Os autores dos comentários foram considerados jovens universitários porque esse é o público alvo do site e do blog e porque o texto postado chegou ao conhecimento da primeira autora por meio de um jovem graduando.

No dia 29/05/2012, um estudante de graduação de uma universidade de Porto Alegre (RS) - aqui nomeado João da Silva - postou o texto intitulado "Marcha das Vadias: Liberdade Feminina ou Putaria?". O título do texto permite entrever o repertório interpretativo empregado pelo autor para falar sobre a Marcha das Vadias ocorrida dias antes, pois sugere dúvida quanto ao objeto da luta do movimento: estariam aquelas mulheres lutando para ter liberdade ou para fazer "putaria"? Essa dúvida indica que, na sociedade em questão, tanto as mulheres teriam motivo para lutar por mais liberdade, quanto precisariam forjar motivos para serem autorizadas a e comportar de modo promíscuo.

João da Silva posicionou-se como um universitário informado, conhecedor do histórico do movimento e apoiador das causas da Marcha no Canadá, ou seja, o protesto contra a culpabilização das mulheres pelos atos de violência cometidos contra elas. Também concordou com os objetivos da Marcha no Brasil: dar destaque à violência contra a mulher e ressaltar a importância da liberdade sexual para a mulher, nas suas palavras. No entanto, desde o início do texto, ele deixou claro que esses objetivos poderiam ter sido - e foram - distorcidos durante a Marcha ocorrida em Porto Alegre.

$\mathrm{O}$ autor alinhou mulheres e homossexuais, uma vez que comparou a Marcha das Vadias às manifestações pelos direitos homossexuais, afirmando que ambos os movimentos caracterizam-se por "apelação", falta de engajamento, informação e seriedade, e desrespeito ao direito dos não participantes de serem poupados de certas imagens. Como exemplo, apresentou a foto de uma mulher, na Marcha, segurando um cartaz com os dizeres "Danço funk sem calcinha, e a 
buceta continua sendo minha”. João da Silva interpretou isso como um pedido de tolerância à "putaria", que se afasta do objetivo da marcha e do ideário feminista.

De acordo com o autor, na Marcha, havia “muita 'vadiazinha' querendo ser vadia sem ter que conviver com o peso que esse termo atribui", algo que ele nomeou como liberação da "promiscuidade pública". O comportamento dos participantes - especificamente das mulheres, pois não foi mencionada a presença de homens na Marcha - foi classificado como desrespeitoso. Tal desrespeito estaria relacionado, sobretudo, às meninas crianças que poderiam ter contato com o protesto de alguma forma, pessoas que, nas palavras de João da Silva, todos querem que sejam "inocentes antes da adolescência". Assim, no texto de João da Silva, identificou-se o repertório interpretativo tradicionalmente empregado para falar sobre as mulheres.

Hegemonicamente, a sexualidade, enquanto prática, é representada como tendo pouca importância para as mulheres (Louro, 2001, 2009), como se elas valorizassem mais o amor e o envolvimento afetivo (Câmara, 2007; Rieth, 2002). Por conseguinte, há uma expectativa de hipossexualização das mulheres (Bordini \& Sperb, 2012), isto é, de que elas não manifestem - ou que o façam de modo discreto - desejos e atrações no campo da sexualidade e de que sejam passivas e monogâmicas em termos sexuais (Miranda-Ribeiro \& Moore, 2003; Neves, 2007; D. B. Santos \& Silva, 2008).

Ao texto em questão, seguiram-se 84 comentários, até o dia 14/06/2012. Em geral, estes tinham a extensão de um parágrafo. Do total de comentários, 54 foram postados por pessoas que se apresentaram como mulheres, 29 por pessoas que se apresentaram como homens e 1 por alguém que não deu indícios quanto ao seu sexo/ gênero. Esses comentários foram, em geral, postados em blocos conforme o sexo/gênero dos usuários; na lista de comentários aparecem, por exemplo, 4 comentários de mulheres em sequência e, logo após, 7 de homens.

No entanto, a análise dos mesmos não se concentrou no sexo/gênero dos seus autores. A razão para isso é que tanto homens quanto mu- lheres apresentaram variabilidade em suas opiniões sobre o texto e a Marcha, bem como nos repertórios interpretativos empregados para falar da sexualidade de mulheres e homens. Tal variabilidade é uma das consequências do tipo de comunicação em blogs, ou seja, a comunicação on-line e assíncrona (não simultânea, cada participante posta seus comentários quando quiser), como encontraram Lagan, Sinclair e Kernohan (2011).

\section{Repertório Interpretativo Tradicional}

Um dos repertórios interpretativos presentes nos comentários foi o mesmo utilizado por João da Silva. Segundo esse repertório, a mulher deve zelar pela sua imagem correspondendo ao estereótipo da hipossexualização. Assim, a liberdade sexual para a mulher teria de ocorrer, como diz M7, "entre quatro paredes, se ela 'se der ao respeito' e não falar sobre a própria sexualidade", uma vez que a "integridade feminina" está relacionada à discrição, à parcimônia e à passividade. Comportamentos que fazem jus a essa integridade são: não mostrar “'demais' o corpo" (M7), "baixar a cabeça", "viver às custas dos homens", "se encaixar num padrão de beleza absurdo" (M38).

Diante disso, tanto o cartaz que aparece na foto postada pelo autor do texto, quanto o ato de mostrar os seios na Marcha (mencionado por vários usuários, mas não por João da Silva), seriam considerados afrontas aos "bons costumes" (M9 e M24) e sinais de que as participantes do movimento não lutavam contra a culpabilização da mulher pelas violências sofridas, mas participaram porque realmente eram "vadias", promíscuas e indiscretas. Isso se depreende dos seguintes comentários:

ah, se eu não conhecesse umas figurinhas que tavam lá... vadiazinha feliz da vida por gritar na rua que é vadia mesmo. nem vem que não tem. mas não dá nada. quem quer ser vadia, pode tambem. mas que o texto do cara ta certo, ah isso tá. (H13)

"Marcha das Vadias: o maior tiro no pé da história. Que pena, eu defendo os direitos da mulher, não de, de fato, vadias" (H11). 
A visão do cartaz e dos seios à mostra na Marcha poderia levar meninas a perder a inocência, sendo que o referido cartaz denegriria a imagem da mulher. Muitas das críticas feitas ao texto dirigiram-se a tais ideias e à sua relação com a assimetria entre homens e mulheres e à objetificação das últimas. Como explicou M39, em parte de seu comentário:

Mulheres, em sua maioria fora de um padrão de beleza hegemonicamente construído e exaltado, que vão à rua mostrar os seios para defender a liberdade são promíscuas,são até "violentas", segundo o autor, mas as garanto que ele não se incomoda com as "gostosonas" do carnaval e da Playboy (que garanto que o autor do texto já deve ter "lido"). A lógica é essa: mulher dominada, doutrinadinha, que se encaixa dentro do estereótipo de fraqueza e passividade é mulher correta, é mulher "íntegra". As outras, somos todas vadias.

Outros usuários também criticaram que a nudez feminina, na Marcha, tenha sido censurada, uma vez que a mesma é valorizada no carnaval e na televisão. Tal censura faz parte desse repertório interpretativo, segundo o qual, o corpo da mulher é um objeto de prazer do homem, o que fica patente no seguinte comentário:

"Vale destacar que ainda existem crianças nesse mundo, mais de 50\% são meninas, e ainda queremos que elas vivam etapas e sejam inocentes antes da adolescência". Novela das oito com cenas de sexo pode, música "ai se eu te pego" no último volume em todos os cantos da cidade pode, um cara de 50 anos passar por mim na rua e me chamar de gostosa, princesa e o escambau em meus plenos 11 anos pode e mulheres com seus seios desnudos protestando por respeito não pode? Olha cara, aquilo do velho babão é sério. Eu me sentia extremamente violentada e desrespeitada quando isso acontecia, e nem entendia porque, pois eu era uma criança. E essa minha inocência, quem devolve? E agora não posso protestar contra isso e garantir que no futuro meninas não sentirão o que eu senti? Agora não posso mostrar meus peitos em protesto porque fere ao pudor sen- do que a globeleza e as memninas da playboy podem? (ah sim, se for para admiração e proveito único do público masculino tudo bem, o problema é quando há vantagens para nós). (M41)

É evidente, portanto, que esse repertório extrapola o tópico sexualidade da mulher e foi comumente usado para falar das mulheres e dos homens, em geral. Hegemonicamente, há uma associação entre o feminino e a delicadeza, a docilidade, a obediência, características comumente relacionadas ao corpo, como se nascessem com a mulher (Friederichs, 2008). Algumas das características atribuídas à feminilidade nos comentários são heranças do sistema patriarcal, como a representação do corpo da mulher como objeto - mais especificamente, objeto para o prazer dos homens (Friederichs, 2008).

A objetificação das mulheres depende da atribuição a elas de um posicionamento passivo, não apenas no campo da sexualidade, que até hoje é identificado na cultura brasileira, em contraposição à associação entre os homens e o posicionamento ativo (Nardi, 2010; Neves, 2007; Oliveira, 2010). Essa oposição entre homens e mulheres serve de base para o repertório interpretativo em questão. Tal oposição e tal repertório fazem parte de um sistema hegemônico, vigente desde o século XX, que tem a heterossexualidade como norma e inclui a oposição, supostamente natural, entre homens e mulheres, reduzidos a uma definição única de masculinidade e de feminilidade, como se existisse uma essência feminina/masculina (Butler, 2003; Connel, 1995; Louro, 2009; Scott, 1995).

Nesse sistema hegemônico, homens e mulheres não somente se encontram em oposição, mas diferentes valores são atribuídos a uns e outros (Louro, 2001). Fry e MacRae (1991), por exemplo, mostraram que, para alguns grupos no Brasil, os indivíduos que estão em uma posição ativa - não apenas no âmbito da sexualidade encontram-se no alto da hierarquia social. Os significados associados à atividade e à passividade dizem respeito, respectivamente, ao modelo de masculinidade e de feminilidade, alinhando, então, a mulher e o estereótipo do homossexual em uma posição inferior (Fry \& MacRae, 1991), 
o que se vê na crítica de João da Silva, ao comparar a Marcha das Vadias aos movimentos pelos direitos homossexuais.

Uma variante - ainda mais conservadora - desse repertório tradicionalmente empregado para interpretar a sexualidade também foi identificada nos comentários ao texto de João da Silva. De acordo com esse repertório, uma mulher "liberada sexualmente" seria algo "apelativo demais", como explica M12. Nas palavras de H27:

Por último, quem dos leitores e replicantes do teu texto parou pra pensar em quantas vezes passou em local público e viu duas crianças de nao mais que 12 anos se beijando quase que em ato sexual e nao pensaram "que mundo é esse em que estamos, duas crianças fazendo tal baixaria" provavelmente será a filha de um deles que vai abrir alguma pagina do nosso maior meio de comunicaçao rede globo e vai ler marcha das vadias e peitos de fora. Num país onde o número de casamentos duradouros diminui a cada ano por nao cultivarmos a tradiçao familiar, onde homem cumpre com deveres de homem e mulheres os de mulheres. Bom sei que nao vamos mudar a cabeça de quem pensa que é legal purficar uma palavra usada para as que vão ser solteiras e sem familia. Mas depois que mudar, nao tem mais volta. Alias, alguem já viu um avô reclamando de uma avó? Acho dificil. Agora com certeza Alguem já ouviu um amigo reclamar de uma namorada e suas modernidades. Pois bem, se querem igualdade, que comecem botando o lixo de casa pra fora $\mathrm{e}$ nao comprando fast food para os filhos.

Isto é, qualquer referência à sexualidade é uma indecência e se configura como um perigo à instituição familiar. A emancipação feminina ameaça o status quo e nem mesmo a objetificação do corpo da mulher para o prazer do homem seria autorizada, pois atentaria contra os "bons costumes". Segundo esse repertório interpretativo, se a "mulher anda de short curto a culpa dos abusos, comentários ofensivos e até mesmo do estupro é dela" (M37), considerando-se também que a contraparte da hipossexualização da mulher é a representação hegemônica do homem como hipersexualizado, vítima de uma sexualidade praticamente incontrolável (Câmara, 2007; Heilborn, 2006; Miranda-Ribeiro \& Moore, 2003; D. B. Santos \& Silva, 2008). Nesse sentido, M34 defendeu: "SE, não queres sofrer algum risco, NÃO SE EXPONHA A ELE”.

\section{Repertório Interpretativo "Feminazismo"}

A oposição e a assimetria entre homens e mulheres também estão presentes em outros repertórios interpretativos identificados nos comentários ao texto de João da Silva. Um deles poderia ser intitulado "feminazismo", uma contração dos termos feminismo e nazismo, fazendo referência ao ideal de um grupo de subjugar outro. Tal repertório, assim como o tradicional, foi empregado para interpretar não apenas a sexualidade feminina, mas as mulheres e os homens em geral, o que fica claro nas seguintes passagens retiradas de um comentário de $\mathrm{H} 20$ :

Feminazis, sim, feminazis, pois o termo feminista se desvirtuou há muito tempo, não querem nenhum tipo de igualdade, e sim uma submissão do homem à mulher.

A marcha seria levada a sério se buscassem, por exemplo, uma forma de ajudar mulheres vítimas de violência doméstica, um dos últimos resquícios de uma cultura machista, ao invés de somente dizerem "me deixem dançar funk sem calcinha". O que, vendo pelas fotos do evento, era o perfil geral das manifestantes. Isso parece, com o perdão das palavras, uma pura vontade de aparecer, "causar", de meia dúzia de barangas mal-amadas. A única oportunidade na vida delas de mostrar os seios para alguém. E imagine, dizer uma asneira dessas é completamente "normal" e "aceitável", mas se o cara disser em um desses funks que quer "o direito de ser canalha", aí é repugnante, ofensivo e machista. Aliás, é curioso observar o comportamento das participantes da tal marcha: Muitas usam a retórica da igualdade, mesmo não praticando-a, porém perdem a linha quando postam uma montagem irônica de uma mulher dizendo "exijo o alistamento obrigatório feminino". O que é nada bizarro, afinal, isso também faz parte 
da igualdade. Sou $100 \%$ a favor da igualdade entre sexos.

Mas igualdade não é a mesma coisa que regalias. Igualdade é um conjunto de direitos e deveres, garantias e obrigações sociais, obrigações essas devidamente esquecidas por grupos extremistas e supremacistas.

Conforme o repertório "feminazismo", a emancipação da mulher, também no âmbito sexual, seria parte de um projeto de dominação da mulher em relação ao homem. Esse seria um projeto encabeçado por mulheres feministas que não se enquadram no padrão de beleza e, por conta disso, não são bem sucedidas nos relacionamentos afetivo-sexuais ("barangas mal-amadas"). $\mathrm{O}$ repertório em questão, então, utiliza-se do estereótipo da feminista, ou seja, feia, sexualmente desinteressante e, por isso, mal-amada, com dificuldades para se relacionar (Marson, 1996; Nogueira, 2001), distante do ideal de mulher.

Essas mulheres viveriam a sexualidade de maneira indiscreta ("vontade de aparecer, "causar"") e aproveitariam a luta pela igualdade de gênero para obter regalias na relação com os homens. As supostas vantagens obtidas pelas mulheres apenas por serem mulheres e a confusão entre isonomia e igualdade foram também referidas por outros pesquisadores. Capelle, Silva, Boas e Brito (2002), por exemplo, em estudo sobre as relações de gênero na Polícia Militar, observaram o quanto policiais homens consideravam como regalias a licença-maternidade, a não participação em atividades arriscadas e outros aspectos do tratamento destinado às mulheres na instituição. Tal entendimento também se apresenta no campo da sexualidade, como sugeriu H9, falando sobre a decisão, em um casal, sobre quem paga a conta: "Rachamos, eu pago ou tu paga, mulher? Feminismo quando convém...".

\section{Repertório Interpretativo Simetria versus Assimetria}

A redução de homens e mulheres a uma definição única que os contrapõe (Connel, 1995; Scott, 1995) fundamenta outro repertório interpretativo utilizado para comentar o texto de João da Silva. Tal repertório destacou-se por suas particularidades, que levam a interpretações atípi- cas sobre a sexualidade da mulher, centrando-se na questão da simetria versus assimetria entre mulheres e homens. Segundo um dos formatos sob o qual esse repertório se apresentou, a sexualidade da mulher seria interpretada de acordo com os padrões hegemônicos de sexualidade masculina. Enfatiza-se a simetria entre homens e mulheres e a igualdade sexual significaria, então, que a mulher deve se comportar tal qual um típico homem. Nas palavras de M33:

Vou de roupa curta pra festa e nem por isso sou estuprada e nunca soube de ninguém que sofreu abuso por causa da roupa. $\mathrm{Ou}$ seja, aí as vadias já perdem todo o argumento. Se tu tá andando de roupa curta na rua e te assobiam e falam coisas que tu não gosta, por que tu não faz o mesmo quando passa um homem sem camisa? Vamos, fale uma grosseria.

Como explica Soihet (2008) sobre visões equivocadas do feminismo, existem entendimentos a seu respeito que o tomam como um incentivo a uma disputa entre homens e mulheres e não como uma busca por igualdade de direitos $\mathrm{e}$ de condições. Parte do movimento feminista no Brasil reivindicou, justamente, que as mulheres fossem tratadas como os homens. Para tal, algumas feministas adotaram referenciais masculinos e renegaram os femininos (Marson, 1996).

Com base nessa ideia de que mulheres e homens formariam dois grupos homogêneos em oposição e considerando a busca pela sua equiparação em termos comportamentais, pode ocorrer um empobrecimento das possibilidades no campo da sexualidade. De fato, alguns autores (Milnes, 2004; Stainton Rogers \& Stainton Rogers, 2001) têm salientado que o estímulo à igualdade sexual e à liberdade sexual da mulher diminuiu as possibilidades das mulheres, pressionando-as a agir de acordo com o modelo de sexualidade masculina.

Contrapondo-se a esse entendimento, identificou-se outro formato sob o qual o repertório em questão se apresentou nos comentários analisados. Esse formato também se fundamenta na oposição entre mulheres e homens e opera de modo a reduzir as possibilidades das mulheres e dos homens - no âmbito sexual. Conforme tal 
repertório, o modelo de sexualidade da mulher deve ser mantido e as mudanças em termos de igualdade sexual devem agir sobre a sexualidade dos homens, tomando como base o modelo feminino. Isso fica patente no comentário a seguir:

Acho que a motivação para a marcha é extremamente válida, nisso se tem toda a razão. Mas acho que algumas mulheres se perderam no meio do caminho. Não podemos confundir liberdade com libertinagem. Muitas vezes a mulher exige ter "direitos" (entre aspas mesmo) que o homem tem, como ficar com várias pessoas do sexo oposto sem ser considerado sem-vergonha. Em vez de corrigir os homens, há quem queira se rebaixar ao nível deles. Precisamos é consertar a sociedade, nivelar por cima, e não por baixo. Sair seminua na rua com uma faixa é muito fácil, difícil é dar e exigir respeito, dar educação para os filhos e ser mulher de verdade, e não uma adolescente revoltada. (M19)

Como se observa, segundo essa interpretação, o modelo de hipossexualização feminina é estimulado e, inclusive, tomado como um ideal a ser imposto aos homens. Conforme descreve Marson (1996) acerca de um outro momento do movimento feminista no Brasil, passa-se a valorizar a cultura feminina, rejeitar a incorporação pelas mulheres de valores masculinos considerados negativos e incentivar a adoção de valores femininos por parte dos homens.

\section{Repertório Interpretativo Mulher Protagonista}

Dentre os repertórios interpretativos presentes nos comentários ao texto de João da Silva, o único que se afastou da oposição entre homens e mulheres e do reducionismo de significados associados às sexualidades de uns e de outros é o que entende as mulheres como protagonistas de suas sexualidades, atribuindo-lhes agência no que tange ao seu posicionamento, escolhas e comportamentos. Esse repertório está em linha com a revolução sexual que estaria ocorrendo, desde as últimas décadas do século XX, em termos de permissividade, com ênfase no livre-arbítrio sexual, aparente na transformação ocorrida na autonomia sexual da mulher (Giddens, 1993).
Tal repertório também extrapola a questão sexual e foi empregado para interpretar as mulheres em geral, tendo sido utilizado em grande parte dos comentários que criticaram o texto sobre a Marcha das Vadias. Tais comentários, comumente, foram produzidos por usuários que se nomearam como mulheres. Isso pode explicar o porquê do uso, em tantos desses comentários, do pronome "nós" para se referir às "vadias", às participantes da Marcha, às mulheres que são ativas na luta pelos seus direitos, que participam politicamente promovendo passeatas com esse intuito, que defendem sua liberdade gritando palavras de ordem.

Esse repertório, então, vai de encontro ao padrão hegemônico de feminilidade, pois foi usado para falar de mulheres que, como definiu M1, percebem que "falar abertamente sobre sexo não é feio, querer gozar não é feio". Ressalta-se que também se identificou o seu emprego por usuários nomeados como homens, por exemplo:

João, você deve ter muito medo de mulher!!! Mais ainda de for uma mulher que vive plenamente sua sexualidade, que na sua opinião deve ser uma vadia, certo? Todo o apoio a essas mulheres corajosas, que tem muito mais coragem pra viver a vida que o coitado desse blogueiro. (H21)

Segundo esse repertório, a mulher é dona do seu corpo e decide sobre o mesmo, devendo, portanto, "ser livre pra fazer a 'putaria' que quiser, sem sofrer consequencias fisicas sobre isso" (M1). A liberdade é tomada como um "DIREITO de todos" (M3), mas é com relação a tal aspecto que a oposição entre mulheres e homens aparece nesse repertório, conforme explicitou M42 em resposta ao texto de João:

Me defina o que é uma vadiazinha? Uma mulher que transa com quantos quiser? E como é que se chamam os homens que fazem isso? Modelo a ser seguido? Olha, é por causa de pessoas que pensam como você que eu vou sair às ruas da minha cidade e gritar contra toda a violência física, moral e principalmente simbólica que nos foi imposta.

Isto é, esse repertório considera que a mulher tem agência sobre sua vida e sua sexualida- 
de, opondo-se à sua interpretação como objeto, ou "mercadoria" (M3). Parte desse entendimento fundamenta-se em uma concepção individualista sobre a sexualidade e as pessoas, em geral. Isso se depreende da apologia a uma liberdade total e sem consequências, como fica claro nas seguintes passagens:

"ser dona do corpo dela e fazer o que ela quiser com ele, sem julgamentos" (M8).

"Liberdade de ser aquilo que quisermos ser, sem repressões por isso" (M3).

"Corrigir homens por ficarem com várias pessoas do outro sexo? Sério? O pênis é meu e coloco onde quero e quantas vezes quiser, a vagina é dela e ela coloca o que quiser e quantas vezes quiser" (H18).

Assim, o repertório em questão permite uma gama maior de interpretações acerca da sexualidade da mulher - e também do homem, estando mais próximo da busca feminista pela desestabilização dos tradicionais significados associados aos homens e às mulheres (Marson, 1996). A maior possibilidade de interpretações deve-se ao questionamento à ideia de uma essência do masculino e do feminino e de uma oposição entre ambos (Connel, 1995; Scott, 1995), propiciando, então, o aparecimento de significações da sexualidade feminina que não tomam a sexualidade masculina como parâmetro.

\section{Considerações Finais}

Não foi identificada muita interação entre os usuários do blog. Poucos comentários foram elaborados em resposta a outros, a sua maioria concentrando-se no texto postado. De fato, Bordini e Sperb (2013) encontraram indícios de pouca interação nas discussões em grupos de comunicação on-line e assíncrona. Ainda assim, as discussões em blogs, como a analisada no presente estudo, configuram-se como espaços que permitem a construção interacional de significados (Lopes, 2010).

$\mathrm{Na}$ investigação do processo de negociação dos significados associados às sexualidades, a análise de uma discussão mostrou-se profícua. Isso pode ser explicado pela importância da linguagem em tal processo, já que o discurso não tem apenas um papel regulador, mas também produtor de sentidos (Butler, 1999). A variedade de repertórios encontrados salienta que não existe só um tipo de homem e um tipo de mulher e que a natural oposição entre ambos é uma construção, que pode, portanto, ser questionada (Butler, 2003; Connel, 1995; Louro, 2009; Scott, 1995).

Apesar da frequente presença do repertório interpretativo tradicional, a negociação dos significados atribuídos às sexualidades e da influência do gênero sobre tais significados chamou atenção. Por meio de comentários, em sua maioria, agressivos ou irônicos, os jovens universitários relativizaram os padrões hegemônicos de gênero que incluem a hipossexualização da mulher e seu posicionamento passivo e a hipersexualização do homem e seu posicionamento ativo (Bordini \& Sperb, 2012; Fry \& MacRae, 1991). Isso fica mais evidente quando se retomam comentários como:

"A lógica é essa: mulher dominada, doutrinadinha, que se encaixa dentro do estereótipo de fraqueza e passividade é mulher correta, é mulher 'íntegra'. As outras, somos todas vadias" (M39).

"Todo o apoio a essas mulheres corajosas, que tem muito mais coragem pra viver a vida que o coitado desse blogueiro" (H21).

"Me defina o que é uma vadiazinha? Uma mulher que transa com quantos quiser? E comé que se chamam os homens que fazem isso? Modelo a ser seguido?" (M42).

"Corrigir homens por ficarem com várias pessoas do outro sexo? Sério? O pênis é meu e coloco onde quero e quantas vezes quiser, a vagina é dela e ela coloca o que quiser e quantas vezes quiser" (H18).

Destacou-se, assim, a existência de diversas interpretações sobre as sexualidades das pessoas, independentemente do gênero. Essa variabilidade revela que os padrões hegemônicos são sempre acompanhados por outras identidades que não correspondem aos valores dominantes, aquelas que são tidas como identidades desviantes (Butler, 2003). Com isso, abre-se caminho para modificações no que diz respeito às masculinidades, feminilidades e sexualidades. 


\section{Referências}

Bordini, G. S., \& Sperb, T. M. (2012). Concepções de gênero nas narrativas de adolescentes. Psicologia: Reflexão e Crítica, 25(4), 738-746. doi:10.1590/S0102-79722012000400013

Bordini, G. S., \& Sperb, T. M. (2013). Grupos focais online e pesquisa em Psicologia: Revisão de estudos empíricos entre 2001 e 2011. Interação em Psicologia, 17(2), 195-205. doi:10.5380/psi. v17i2.28480

Butler, J. P. (1999). Corpos que pesam: Sobre os limites discursivos do "sexo". In G. L. Louro (Ed.), O corpo educado. Pedagogias da sexualidade (pp. 151-172). Belo Horizonte, MG: Autêntica.

Butler, J. P. (2003). Problemas de gênero: Feminismo e subversão da identidade (R. Aguiar, Trad.). Rio de Janeiro, RJ: Civilização Brasileira.

Câmara, A. P. (2007). Gênero e sexualidade na Revista Sexy: Um roteiro para a masculinidade heterossexual (Dissertação de mestrado, Programa de Pós-Graduação em Educação, Universidade Federal do Rio Grande do Sul, Porto Alegre, RS, Brasil).

Capelle, M. C. A., Silva, A. L., Boas, L. H. de B. V., \& Brito, M. J. de. (2002). Representações das relações de gênero no espaço organizacional público. Revista de Administração Pública, 36(2), 253-275.

Connel, R. W. (1995). Políticas da masculinidade. Educação e Realidade, 20(2), 185-206.

De Fina, A., \& Georgakopoulou, A. (2011). Analyzing narrative: Discourse and sociolinguistic perspectives. Cambridge, UK: Cambridge University Press.

De Melo, G. C. V., \& Lopes, L. P. da M. (2013). As performances discursivo-identitárias de mulheres negras em uma comunidade para negros na Orkut. DELTA: Documentação de Estudos em Lingüística Teórica e Aplicada, 29(2), 237 265. doi:10.1590/S0102-44502013000200003

Edley, N. (2001). Analysing masculinity: Interpretative repertoires, ideological dilemas and subject positions. In M. Wetherell, S. Taylor, \& S. J. Yates (Eds.), Discourse as data: A guide for analysis (pp. 189-228). London: Sage.

Ferreira, G. (2013). Feminismo e redes sociais na Marcha das Vadias no Brasil. Revista Ártemis, 15(1), 33-43.
Fogliatto, D. (2013, 26 jun.). Pelo fim do machismo, Marcha das Vadias reúne milhares em Porto Alegre. Sul21. Recuperado em http://www.sul21. com.br/jornal/pelo-fim-do-machismo-marcha-das-vadias-reune-milhares-em-porto-alegre/

Fogliatto, D. (2014, 27 abr.). Com dois trajetos, Marcha das Vadias de Porto Alegre reúne centenas pelo fim da violência contra a mulher. Sul21. Recuperado em http://www.sul21.com.br/jornal/ com-dois-trajetos-marcha-das-vadias-de-porto-alegre-reune-centenas-pelo-fim-da-violencia-contra-a-mulher/

Fragoso, S., Recuero, R., \& Amaral, A. (2011). Métodos de pesquisa para internet. Porto Alegre, RS: Sulina.

Friederichs, M. C. (2008). Corpos escritos na internet: Representações do corpo em blogs. Recuperado em http://www.fazendogenero8.ufsc.br/ sts/ST53/Marta_Cristina_Friederichs_53.pdf

Fry, P., \& MacRae, E. (1991). O que é homossexualidade (7. ed.). São Paulo, SP: Brasiliense.

Giddens, A. (1993). A transformação da intimidade: Sexualidade, amor \& erotismo nas sociedades modernas (M. Lopes, Trad.). São Paulo, SP: Editora da Universidade Estadual Paulista "Júlio de Mesquita Filho".

Gouveia, V. V., Souza, L. E. C., Vione, K. C., Cavalcanti, M. F. B., Santos, W. S., \& Medeiros, E. D. (2011). Motivações para responder sem preconceito: Evidências de uma medida frente a gays e lésbicas. Psicologia: Reflexão $e$ Crítica, 24(3), 458-466. doi:10.1590/S010279722011000300006

Guimarães, A. F. P. (2009). O desafio histórico de "tornar-se um homem homossexual": Um exercício de construção de identidades. Temas em Psicologia, 17(2), 553-567.

Heilborn, M. L. (2006). Entre as tramas da sexualidade brasileira. Estudos Feministas, 14(1), 43-59. doi:10.1590/S0104-026X2006000100004

Heilborn, M. L., Aquino, E. M. L., Bozon, M., \& Knauth, D. R. (2006). O aprendizado da sexualidade: Reprodução e trajetórias sociais de jovens brasileiros. Rio de Janeiro, RJ: Garamond.

Helene, D. (2013). A Marcha das Vadias: O corpo da mulher e a cidade. Redobra, 11, 68-79.

Houaiss, A., \& Villar, M. de S. (2010). Minidicionário Houaiss da língua portuguesa (4. ed.). Rio de Janeiro, RJ: Objetiva. 
Lagan, B. M., Sinclair, M., \& Kernohan, W. G. (2011). What is the impact of the internet on decision-making in pregnancy? A global study. Birth Issues in Perinatal Care, 38(4), 336-345. doi:10.1111/j.1523-536X.2011.00488.x

Lopes, L. P. da M. (2010). Os novos letramentos digitais como lugares de construção de ativismo político sobre sexualidade e gênero. Trabalhos em Linguística Aplicada, 49(2), 393-417. doi:10.1590/S0103-18132010000200006

Louro, G. L. (2001). Currículo, gênero e sexualidade. Porto, Portugal: Porto Editora.

Louro, G. L. (2004). Gênero, sexualidade e educação: Uma perspectiva pós-estruturalista (7. ed.). Petrópolis, RJ: Vozes.

Louro, G. L. (2007). Gênero, sexualidade e educação: Das afinidades políticas às tensões teórico-metodológicas. Educação em Revista, 46, 201-218. doi:10.1590/S0102-46982007000200008

Louro, G. L. (2008). Gênero e sexualidade: Pedagogias contemporâneas. Pró-Posições, 19(2), 17-24.

Louro, G. L. (2009). Heteronormatividade e homofobia. In R. D. Junqueira (Ed.), Diversidade sexual na Educação: Problematizações sobre a homofobia nas escolas (pp. 85-93). Brasília, DF: Ministério da Educação, Secretaria de Educação Continuada, Alfabetização e Diversidade.

Luccio, F. Di, \& Nicolaci-da-Costa, A. M. (2010). Blogs: De diários pessoais a comunidades virtuais de escritores/leitores. Psicologia: Ciência e Profissão, 30(1), 132-145. doi:10.1590/S141498932010000100010

Marson, M. I. (1996). Da feminista "macha" aos homens sensíveis: $\mathrm{O}$ feminismo no Brasil e as (des) construções das identidades sexuais. Cadernos AEL, 2(3-4), 69-110.

Milnes, K. (2004). What lies between romance and sexual equality? A narrative study of young women's sexual experiences. Sexualities, Evolution \& Gender, 6(2-3), 151-170. doi:10.1080 $/ 14616660412331325169$

Miranda-Ribeiro, P., \& Moore, A. (2003). Papéis de gênero e gênero no papel: Uma análise de conteúdo da Revista Capricho, 2001-2002. Belo Horizonte, MG: Editora da Universidade Federal de Minas Gerais.

Nardi, H. C. (2010). Sexo e poder nas tramas pós(?) identitárias: Reflexões sobre a prostituição masculina. In L. P. da M. Lopes \& L. C. Bastos (Eds.), Para além da identidade: Fluxos, movimentos e trânsitos (pp. 215-234). Belo Horizonte, MG: Editora da Universidade Federal de Minas Gerais.

Neves, A. S. A. (2007). As mulheres e os discursos genderizados sobre o amor: A caminho do "amor confluente" ou o retorno ao mito do "amor romântico"? Estudos Feministas, 15(3), 609-627. doi:10.1590/S0104-026X2007000300006

Nogueira, C. (2001). Feminismo e discurso do género na Psicologia Social. Psicologia \& Sociedade, 13(1), 107-128.

Oliveira, L. (2010). Entre discursos, jeitos e gestos: Performance de gênero e sexualidade no mercado erótico de travestis e cross-dressers. In L. P. da M. Lopes \& L. C. Bastos (Eds.), Para além da identidade: Fluxos, movimentos e trânsitos (pp. 235-259). Belo Horizonte, MG: Editora da Universidade Federal de Minas Gerais.

Paz, C. R. (2003). A cultura Blog: Questões introdutórias. Revista FAMECOS: Mídia, Cultura e Tecnologia, 22, 66-72.

Potter, J., \& Wetherell, M. (1987). Discourse and social psychology: Beyond attitudes and behaviour. London: Sage.

Rieth, F. (2002). A iniciação sexual na juventude de mulheres e homens. Horizontes Antropológicos, $8(17), 77-91$.

Santos, D. B., \& Silva, R. C. (2008). Sexualidade e normas de gênero em revistas para adolescentes brasileiros. Saúde e Sociedade, 17(2), 22-34. doi:10.1590/S0104-12902008000200004

Santos, M. B. P., Penteado, C. L. de C., \& Araújo, R. de P. A. (2009). Metodologia de pesquisa de blogs de política: Análise das eleições presidenciais de 2006 e do movimento "cansei". Revista de Sociologia e Politica, 17(34), 159-181. doi:10.1590/S0104-44782009000300012

Scott, J. (1995). Gênero: Uma categoria útil de análise histórica. Educação e Realidade, 20(2), 71-99.

Silva, T. T. (Ed.). (2003). Identidade e diferença: A perspectiva dos Estudos Culturais (2. ed.). Petrópolis, RJ: Vozes.

Soihet, R. (2008). Mulheres investindo contra o feminismo: Resguardando privilégios ou manifestação de violência simbólica? Estudos de Sociologia (Araraquara), 13(24), 191-207. 
Stainton Rogers, W., \& Stainton Rogers, R. (2001). The psychology of gender and sexuality. Buckingham, UK: Open University Press.

Valli, G. P., \& Cogo, A. L. P. (2013). Blogs escolares sobre sexualidade: Estudo exploratório documental. Revista Gaúcha de Enfermagem, 34(3), 31-37. doi:10.1590/S1983-14472013000300004

Veja as marchas da Maconha e das Vadias em Porto Alegre. (2012, 28 maio). Sul21. Recuperado em http://www.sul21.com.br/jornal/veja-asmarchas-da-maconha-e-das-vadias-em-portoalegre/
Weeks, J. (2003). Sexuality (2nd ed.). London: Routledge.

Wetherell, M. (1998). Positioning and interpretative repertoires: Conversation analysis and post-structuralism in dialogue. Discourse and Society, 9(3), 387-412. doi:10.1177/0957926598009003005

Recebido: 23/06/2014

$1^{a}$ revisão: 09/10/2014

Aceite final: 13/10/2014 